\title{
New Darwin wasps (Hymenoptera, Ichneumonidae, Tersilochinae, Tryphoninae) from the Eastern Palaearctic region
}

\author{
Dmitri R. Kasparyan', Andrey I. Khalaim ${ }^{1,2}$ \\ I Zoological Institute of the Russian Academy of Sciences, St. Petersburg, Russia $\mathbf{2}$ Facultad de Ingenieria y \\ Ciencias, Universidad Autónoma de Tamaulipas, Cd. Victoria, Mexico \\ Corresponding author: Andrey I. Khalaim (ptera@mail.ru)
}

Academic editor: Vladimir Gokhman | Received 15 May 2021 | Accepted 14 June 2021 | Published 24 August 2021

http://zoobank.org/AA7E307D-6408-4FF9-8AC5-0B707FB07DB6

Citation: Kasparyan DR, Khalaim AI (2021) New Darwin wasps (Hymenoptera, Ichneumonidae, Tersilochinae, Tryphoninae) from the Eastern Palaearctic region. In: Proshchalykin MYu, Gokhman VE (Eds) Hymenoptera studies through space and time: A collection of papers dedicated to the $75^{\text {th }}$ anniversary of Arkady S. Lelej. Journal of Hymenoptera Research 84: 115-126. https://doi.org/10.3897/jhr.84.68719

\begin{abstract}
In this study, we describe two remarkable species, Ctenochira arkadyi Kasparyan, sp. nov. (Tryphoninae) from southern Siberia (Russia), and Probles arkadyi Khalaim, sp. nov. (Tersilochinae) from Japan. These two species are named in honour of our colleague and friend, an expert in Aculeata (Hymenoptera), Russian entomologist, Prof. Arkady Lelej, in honour of his $75^{\text {th }}$ birthday. The recently described European species, Ctenochira magnusi Haraldseide, 2018, is discovered from the Russian Far East; the male of C. magnusi is recorded and described for the first time.
\end{abstract}

\section{Keywords}

Asia, Ctenochira, Japan, new species, parasitoids, Probles, Russia, Siberia

\section{Introduction}

In spite of the extensive study of Darwin wasps (the name suggested for the Ichneumonidae by Klopfstein et al. 2019) in the Eastern Palaearctic region during the past decades, fauna of this region remains understudied and comprises many undescribed taxa. 
Palaearctic species of the large tryphonine genus Ctenochira Förster, 1855 (Tryphoninae) were revised by the first author (Kasparyan 1973) and several new taxa in this genus were described in a series of subsequent publications (Kasparyan and Tolkanitz 1999; Kasparyan and Khalaim 2007; Kasparyan 2013a, 2013b). At present, Ctenochira comprises about 100 species worldwide (Yu et al. 2016), of which 70 species occur in the Palaearctic region (Kasparyan 2019).

Probles Förster, 1869 is a large almost worldwide genus of Tersilochinae with 74 described species, of which over 50 species occur in the Palaearctic region. The European fauna of the genus was revised by Horstmann $(1971,1981)$, and in $21^{\text {st }}$ century new species were described in the Eastern Palaearctic region from China (Khalaim and Sheng 2009), South Korea (Khalaim et al. 2013; Balueva et al. 2014; Khalaim et al. 2017), Russian Far East (Khalaim 2014; Khalaim and Tereshkin 2019), and in the Oriental region from Vietnam (Khalaim 2011, 2018, 2019). However, many Eastern Palaearctic and Oriental species of Probles remain undescribed.

The aims of this study are to describe new species of Tersilochinae and Tryphoninae from the Eastern Palaearctic region and provide new faunistic records.

\section{Material and methods}

The specimens examined in this study were borrowed from or deposited in the following collections: the Matsuyama University, Ehime Pref., Shikoku, Japan (EUM), and the Zoological Institute of the Russian Academy of Sciences, St. Petersburg, Russia (ZISP).

Morphological terms predominantly follow Townes (1969). Layer photographs were taken in ZISP, with an Olympus OM-D digital camera attached to an Olympus SZX10 stereomicroscope, and partially focused images were combined using Helicon Focus Pro (v. 7.6.6) software.

\section{Results and taxonomy}

\section{Subfamily Tersilochinae}

Genus Probles Förster, 1869

\section{Probles (Euporizon) arkadyi Khalaim, sp. nov. http://zoobank.org/B6DAEDD6-1241-42AD-8A42-040BBC871233}

Figs 1-11

Comparison. Probles arkadyi sp. nov. is easily distinguished from other Eastern Palaearctic species of the genus by its unusually small clypeus (Fig. 3) which is 0.6 times as broad as the face (shortest distance between eye margins). A similarly small clypeus is known in the Vietnamese species P. proshchalykini Khalaim, 2019, but the latter species 


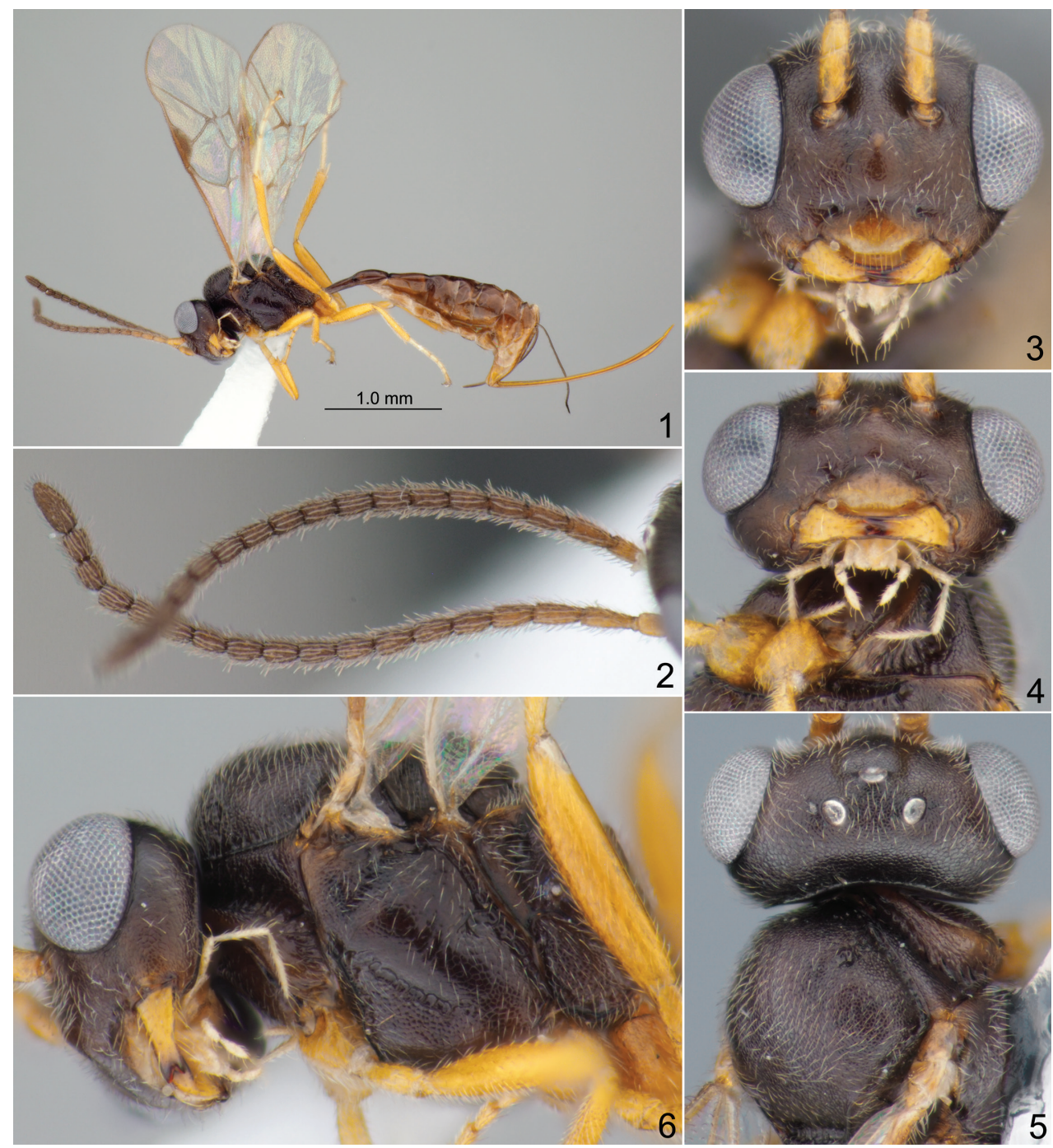

Figures I-6. Probles arkadyi sp. nov., holotype, female I habitus, lateral view $\mathbf{2}$ antennae, dorso-lateral view $\mathbf{3}$ head, front view $\mathbf{4}$ head, ventral view $\mathbf{5}$ head and mesoscutum, dorsal view $\mathbf{6}$ head and mesosoma, lateral view.

has genae strongly swollen behind the eyes (in dorsal view), while in P. arkadyi sp. nov. the genae are distinctly constricted behind the eyes (Fig. 5). Probles arkadyi sp. nov. is also characterized by the long malar space and strongly tapered mandibles (Fig. 4).

Description. Female. Body length $3.2 \mathrm{~mm}$. Fore wing length $2.2 \mathrm{~mm}$.

Head with gena distinctly and roundly constricted posterior to eyes (Fig. 5); gena in dorsal view 0.45 times as long as eye width. Clypeus unusually small, 2.1 times as broad as long and 0.6 times as broad as face (shortest distance between eye margins), smooth, with very fine and sparse punctures in upper half, separated from face by 
sharp furrow (Fig. 3). Mandible strongly constricted in basal 0.7; width of mandible at level of teeth about 0.4 times width at base; lower tooth almost 1.5 times longer than the upper (Fig. 4). Malar space about 1.1 times as long as basal mandibular width. Flagellum with 16-17 flagellomeres, filiform (Fig. 2); second flagellomere almost twice, flagellomeres 3-5 about 1.8 times, and subapical flagellomeres 1.2 times as long as broad; flagellomeres 4 to 6 (or more) bearing very small subapical finger-shaped structures on outer surface (these structures hardly discernible with a light microscope). Face with median swelling. Face, frons and vertex finely granulate, impunctate, dull. Gena shallowly granulate, impunctate, weakly shining. Occipital carina complete, evenly convex mediodorsally. Hypostomal carina absent (at least in lower part).

Mesosoma almost entirely granulate, impunctate and dull, except for mesopleuron, which is widely smooth and shining centrally above foveate groove (Fig. 6). Notaulus with irregular wrinkles (Fig. 5). Scutellum with lateral longitudinal carinae developed on anterior 0.3-0.4. Upper end of epicnemial carina curved abruptly forward to anterior margin of mesopleuron (Fig. 4). Foveate groove of mesopleuron long, oblique, almost straight, deep and moderately broad, with distinct transverse wrinkles, extending over anterior 0.6 of mesopleuron, almost reaching epicnemial carina anteriorly (Fig. 6). Propodeum with narrow to moderately broad basal area which is 2.5-3.5 times as long as broad and about half as long as apical area (Fig. 8). Propodeal spiracle separated from pleural carina by about 2.0 diameters of spiracle. Apical area slightly impressed along midline, narrowly rounded anteriorly (Fig. 8); apical longitudinal carinae complete and reaching transverse carina anteriorly (Fig. 8).

Fore wing (Fig. 7) with second recurrent vein $(2 \mathrm{~m}-\mathrm{cu})$ postfurcal. First abscissa of radius $(\mathrm{Rs}+2 \mathrm{r})$ straight, somewhat longer than width of pterostigma. First and second sections of radius (Rs+2r and Rs) meeting at slightly acute angle. Intercubitus (2rs-m) slightly thickened, about as long as abscissa of cubitus between intercubitus and second recurrent vein (abscissa of $M$ between 2rs-m and 2m-cu). Metacarpus (R1) short, not reaching tip of the wing. Second abscissa of postnervulus (Cu\&2cu-a) present, thus brachial cell is closed posteriorly. Hind wing with nervellus (cu1\&cu-a) weakly reclivous. Legs slender, tarsal claws not pectinate.

First tergite about 3.4 times as long as posteriorly broad, more or less trapeziform in central cross-section; lateral sides of petiole distinctly longitudinally striate before glymma (Fig. 10), petiole dorsally and postpetiole smooth; glymma deep, round, situated at posterior 0.55 of tergite and joining by thin and sharp furrow with ventral part of postpetiole (Fig. 10); in dorsal view, petiole with lateral margins subparallel, postpetiole distinctly widened anteriorly and almost twice broader than petiole (Fig. 9); upper margin of first tergite, in lateral view, nearly straight in anterior 0.7 and distinctly arcuate in posterior 0.3 (Fig. 10). Second tergite 1.5 times as long as anteriorly broad (Fig. 9). Thyridial depression deep and long, 2.5-3.0 times as long as broad, with posterior end rounded (Fig. 9). Ovipositor slender, weakly upcurved, with weak dorsal subapical depression (Fig. 11); sheath twice as long as first tergite (Fig. 1).

Head and mesosoma dark reddish brown (Fig. 6); lower 0.7 of clypeus, mouthparts and mandibles (teeth reddish black) yellow to brownish yellow. Antenna with scape and 


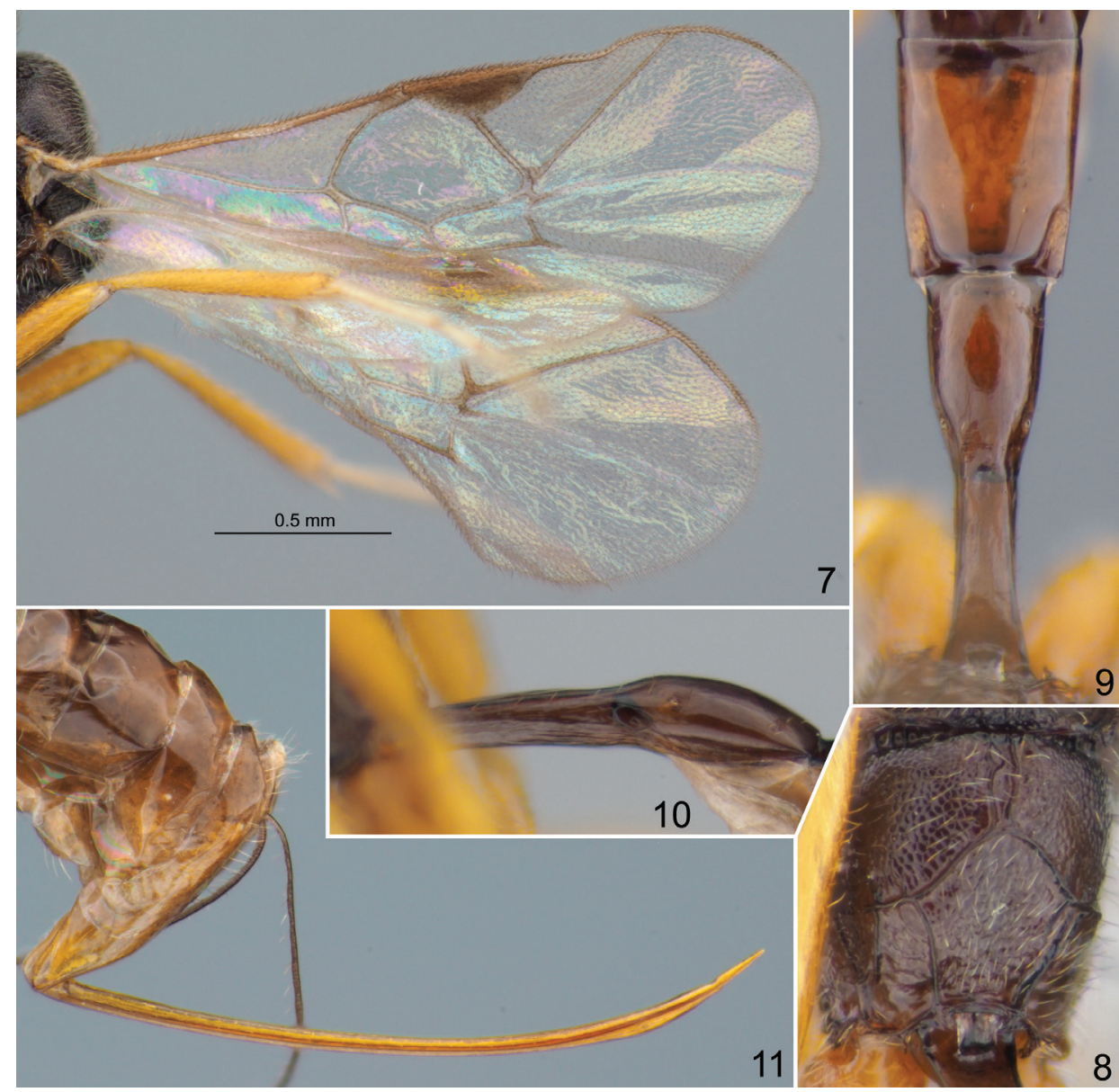

Figures 7-II. Probles arkadyi sp. nov., holotype, female $\mathbf{7}$ wings 8 propodeum, dorsal view 9 base of metasoma, dorsal view $\mathbf{I} \mathbf{0}$ first tergite, lateral view $\mathbf{I} \mathbf{I}$ apex of metasoma with ovipositor, lateral view.

pedicel yellow ventrally and brownish dorsally; flagellum brown with basal flagellomeres yellowish brown. Tegula yellow-brown. Pterostigma brown. Legs brownish yellow; hind coxa slightly darkened with brown. First metasomal tergite dark brown. Metasoma posterior to first tergite predominantly brown, yellowish to pale brown ventrally (Fig. 1).

Male. Unknown.

Etymology. The species is named in honour of the Russian entomologist, an expert in Mutillidae, Prof. Arkady S. Lelej (Vladivostok, Russia).

Material examined. Holotype female (EUM), Japan, Hokkaido I., Sapporo, Hitsu-

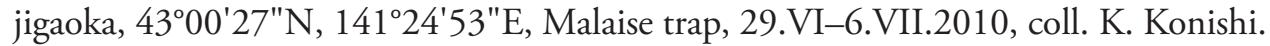

Paratypes. Japan: 1 female (EUM), same data as holotype, but 6-13.VII.2010. 1 female (ZISP), same data, but 27.VI-4.VII.2011. 1 female (ZISP), same data, but 4-11.VII.2011. 1 female (EUM), same data, but 11-18.VII.2011.

Distribution. Japan (Hokkaido I.). 


\section{Subfamily Tryphoninae}

\section{Genus Ctenochira Förster, 1855}

Remarks. Ctenochira is the largest genus of the tribe Tryphonini occurring in the Holarctic and Oriental regions, comprising about 100 species (Yu et al. 2016); the genus is best represented in the boreal and subarctic zones of the Holarctic region. The Nearctic fauna of the genus was revised by Townes and Townes (1949), and Palaearctic species were revised by Kasparyan (Kasparyan 1973, 2013a etc.).

All species of Ctenochira are koinobiont ectoparasitoids of sawfly larvae of the family Tenthredinidae (Hymenoptera: Symphyta); the parasitoid female usually oviposits on exposed, living openly, larvae of the host.

\section{Ctenochira arkadyi Kasparyan, sp. nov.}

http://zoobank.org/E2F68F73-C519-4130-9128-6044D9453A12

Figs $12-18$

Comparison. Ctenochira arkadyi sp. nov. belongs to the C. flavicauda group of species characterized by the presence of the areolet in the fore wing and shortly pectinate tarsal claws. It differs from other species of this group in having metasomal tergites 2-4 distinctly, densely and uniformly punctate, and the propodeum with costulae. Ctenochira arkadyi sp. nov. is similar to the recently described C. magnusi Haraldseide, 2018, but differs from this species (as well as from most other congeners) by the features listed in Table 1.

Description. Female. Fore wing length $6.0 \mathrm{~mm}$.

Antenna with 29 flagellomeres; first flagellomere 4.0 times and second flagellomere 2.5 times as long as broad; combined length of flagellomeres 1 and 2 about 0.9 maximum eye diameter. Apical flagellomeres thin, about 0.6 times as wide as ba-

Table I. Morphological differences between Ctenochira arkadyi sp. nov. and C. magnusi.

\begin{tabular}{lcc}
\hline \multicolumn{1}{c}{ Character } & C. arkadyi sp. nov. & C. magnusi \\
\hline $\begin{array}{l}\text { Pronotum laterally } \\
\text { Mesopleuron }\end{array}$ & evenly punctate & polished, impunctate \\
Costulae on propodeum & with distinct large punctures & present \\
Metasomal tergites & distinctly and evenly punctate & with fine and sparse punctures \\
Fore wing with nervulus & strongly postfurcal & absent \\
Fore femur & 2.2 times as long as broad & impunctate \\
Tarsal claws & with 6-9 dense teeth (Fig. 16) & interstitial or weakly postfurcal \\
Tergite 1 with dorsal carinae & reaching about 0.5 length of tergite & with times as long as broad \\
Apex of hypopygium ventrally & polished, with long setae & reaching 0.8 length of tergite \\
Face & yellow & matt, with shorter, dense and erect setae \\
Scape of antenna & yellow ventrally & black \\
Tergites 2-4 & only tergite 2 red & black \\
Hind femur & & tergites 2 and 3 (sometimes also 4) red \\
& red, with small dark dorsoapical marking (Fig. 15) & gradually darkening from reddish basally to \\
\end{tabular}




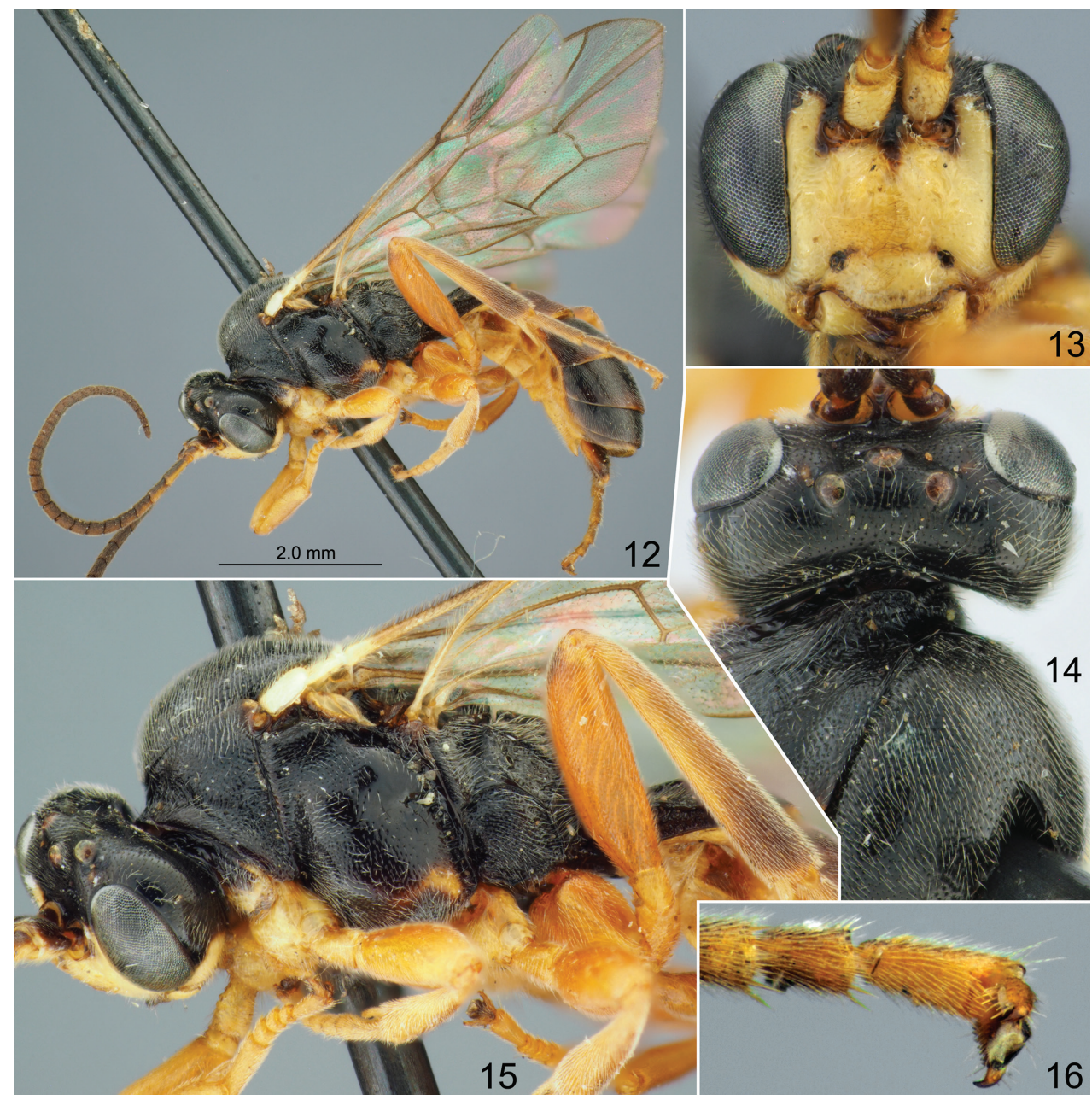

Figures 12-16. Ctenochira arkadyi sp. nov., holotype, female $\mathbf{2}$ habitus, lateral view $\mathbf{1} \mathbf{3}$ head, front view $\mathbf{1 4}$ head, dorsal view $\mathbf{I} \mathbf{5}$ head, mesosoma and base of metasoma, lateral view $\mathbf{1 6}$ apex of hind tarsus.

sal flagellomeres. Sensillae starting on flagellomere 4 and continuing on subsequent flagellomeres. Head (Figs 13, 14) shining, not narrowed behind eyes, temples slightly convex. Face centrally convex and coarsely punctate. Clypeus weakly and evenly convex, polished, finely and sparsely punctate; clypeal foveae small, without setae. Frons with rather dense, even and moderately fine punctures. Temples with fine and sparse punctures. Margins of antennal sockets on frons not raised. Malar space about half as long as basal mandibular width. Oral carina slightly higher than occipital carina, and 0.6 times as long as basal mandibular width.

Thorax smooth, with even, distinct, moderately large and dense punctures. Pronotum with rugosity on transverse impression and lateral lower corner. Mesoscutum without notaulus. Scutellum with lateral carinae on its anterior 0.4. Mesopleuron in upper half and posteriorly smooth, shining, with moderately large punctures which are separated by 
about 1.5 diameters of puncture (Fig. 15); speculum large and polished. Metapleuron with punctures denser (distance between punctures about 0.5-1.0 diameter of puncture); lower margin of metapleuron with deep impression covered with rugae. Propodeum with superficial rugosity, impunctate except for irregular punctures on smooth background on first lateral areas; costulae present, extending from hind part of areola; areola confluent with basal area, its lateral sides parallel. Apical area 0.55 times as high as length of propodeum (measured at midline), with median longitudinal carina distinct.

Fore wing with an areolet (Fig. 12); nervulus strongly postfurcal. Hind wing with nervellus intercepted at lower 0.23 (Fig. 15). Fore femur thick, 2.2 times as long as wide. Fore and mid tarsi shortened. Fore leg with first tarsomere 2.7 times as long as wide, tarsomeres 2-4 transverse. Mid tarsus with first tarsomere 3.0 times as long as wide and 1.4 times shorter than tarsomeres $2-5$ combined. Hind femur 3.5 times as long as wide; length ratio of tarsomeres $1-5$ of hind tarsus $4.8: 2.5: 1.7: 1.2: 2.2$. Tarsal claws apically strongly curved and tapered to a sharp point; claws with relatively short and dense teeth (Fig. 16); fore tarsus with 6 teeth, mid and hind tarsi with 7-9 teeth.

Metasomal tergites smooth, with dense and moderately large punctures; punctures denser on tergites 1-4 (Fig. 17), somewhat finer and sparser on posterior margins of tergites, on posterior half of tergite 4 , and on tergite 5 (subsequent tergites retracted under tergite 5, see Fig. 18). First tergite about 0.9 times as long as wide, its longitudinal median dorsal carinae strong and extending to superficial transverse depression in posterior 0.2 of tergite; interspace between dorsal carinae broad, entirely densely punctate from transverse depression to base; transverse depression with short longitudinal rugae. Second and third tergites strongly transverse, about 0.5 times as long as broad; both tergites with shallow transverse depression just behind middle. Hypopygium large, with large oval desclerotized area medially in basal 0.7 (this area somewhat paler than its light yellow apical and lateral periphery); hypopygium with rather dense, erected and moderately long setae which are shorter than diameters of hind tarsomeres and extending to hind margin of hypopygium (Fig. 18). Ovipositor sheath 2.5 times as long as its median width, with dorsoapical emargination in its apical 0.4 (Fig. 18).

Coloration (Fig. 12). Antenna blackish brown, scape and pedicel light yellow ventrally and flagellomeres 1-3 brownish yellow ventrally. Head black; face, clypeus, lower 0.3 of frontal orbits, palpi, mandible (except for reddish brown teeth), malar space, lower parts of gena and postgena yellow (Fig. 13). Mesosoma black; lower margin of propleuron (above fore coxa), tegula and plates at base of fore wing yellow; lower part of mesopleuron with obscure reddish marking ventrally (Fig. 15). Legs predominantly yellowish red. Fore and mid legs with coxae and trochanters entirely light yellow, and femora, tibiae and tarsi reddish yellow. Hind leg with coxa, trochanters and femur red; femur slightly darkened dorsally at apical 0.1; tibia brownish yellow in basal 0.6 and dark brown in apical 0.4; spurs yellow; hind tarsus brown, tarsomeres 1-3 pale at extreme base. Pterostigma dark brown with proximal 0.25 whitish.

First metasomal tergite black except for yellowish red hind margin; second tergite reddish with two subbasal blackish spots (Fig. 17); subsequent tergites black except for tergites 3 and 4 which are brownish black in posterior $1 / 3$ and with reddish tinge on hind margins (Figs 17, 18). Epipleura and sternites yellow, segments $2-4$ each with 
brownish large sclerotized spot. Ovipositor sheath dark brown, its extreme apex and basal 0.6 latero-ventrally reddish yellow.

Male. Unknown.

Etymology. We are happy to name this new species in honour of Prof. Arkady Lelej, after his $75^{\text {th }}$ birthday and in recognition of his enormous contribution to the taxonomy of Aculeata and his hard work organizing extensive insect studies in the Russian Far East.

Material examined. Holotype female (ZISP), Russia, Transbaikal Territory, railway station Karymskaya, ravine in right bank of Ingoda river, taiga (Pinus, Larix), 28.VI.1975, coll. D.R. Kasparyan.

\section{Ctenochira magnusi Haraldseide, 2018}

Figs 19, 20

Ctenochira magnusi Haraldseide, 2018: 27 [holotype female (Zoologische Staatssammlung, Munich, Germany) (not examined), Norway, Vindafjord, Oppsalsneset, $59.29479^{\circ} \mathrm{N}, 5.52589^{\circ} \mathrm{E}, 40 \mathrm{~m}$, Malaise trap, VI.2016, coll. H. Haraldseide \& E. Thorsen, CollHH1046].

Remarks. This is the first record of C. magnusi from Russia. The male of this species is described here for the first time.

Variation. A female from the Russian Far East possesses hind tarsal claws with teeth slightly denser and concentrated at the base of the claw (Fig. 20) than in material from Europe.

Description. Male. Fore wing length 4.7-6.0 mm.

Antenna with 28-30 flagellomeres, about ten basal flagellomeres thicker than subsequent ones. Head smooth, shining. Face weakly convex in profile, distinctly and rather densely punctate. Frons with distinct moderately dense punctures. Vertex and temple finely and sparsely punctate. Clypeus convex in upper 0.3 , flat in lower part, almost impunctate. Malar space and oral carina behind mandible about 0.5 times as long as basal mandibular width. Pronotum laterally with large polished area, with subparallel striation near collar and at lower corner. Epomia weak. Mesopleuron finely and sparsely punctate, with large polished speculum and almost impunctate below subtegular ridge and next to mesopleural fovea along mesepimeron. Mesoscutum with uniform small and dense punctures. Notaulus very weak or absent. Scutellum with sparse moderately large punctures and distinct lateral carina on its anterior $0.4-0.5$. Tarsal claw of fore leg with 4 (or 5) small teeth in basal 0.8; claw of mid leg with 3 small teeth in basal half; claw of hind leg with 3 teeth in basal 0.4. Metasoma shining, impunctate, tergites 1 and 2 partly with longitudinal striation in posterior half, especially on postmedian transverse impressions; posterior half of tergite 3 and subsequent tergites smooth, with very fine punctures and pubescence.

Coloration. Antenna light brownish, scape and pedicel yellowish white ventrally, two or three basal flagellomeres brownish yellow ventrally. Head black; face, clypeus, 

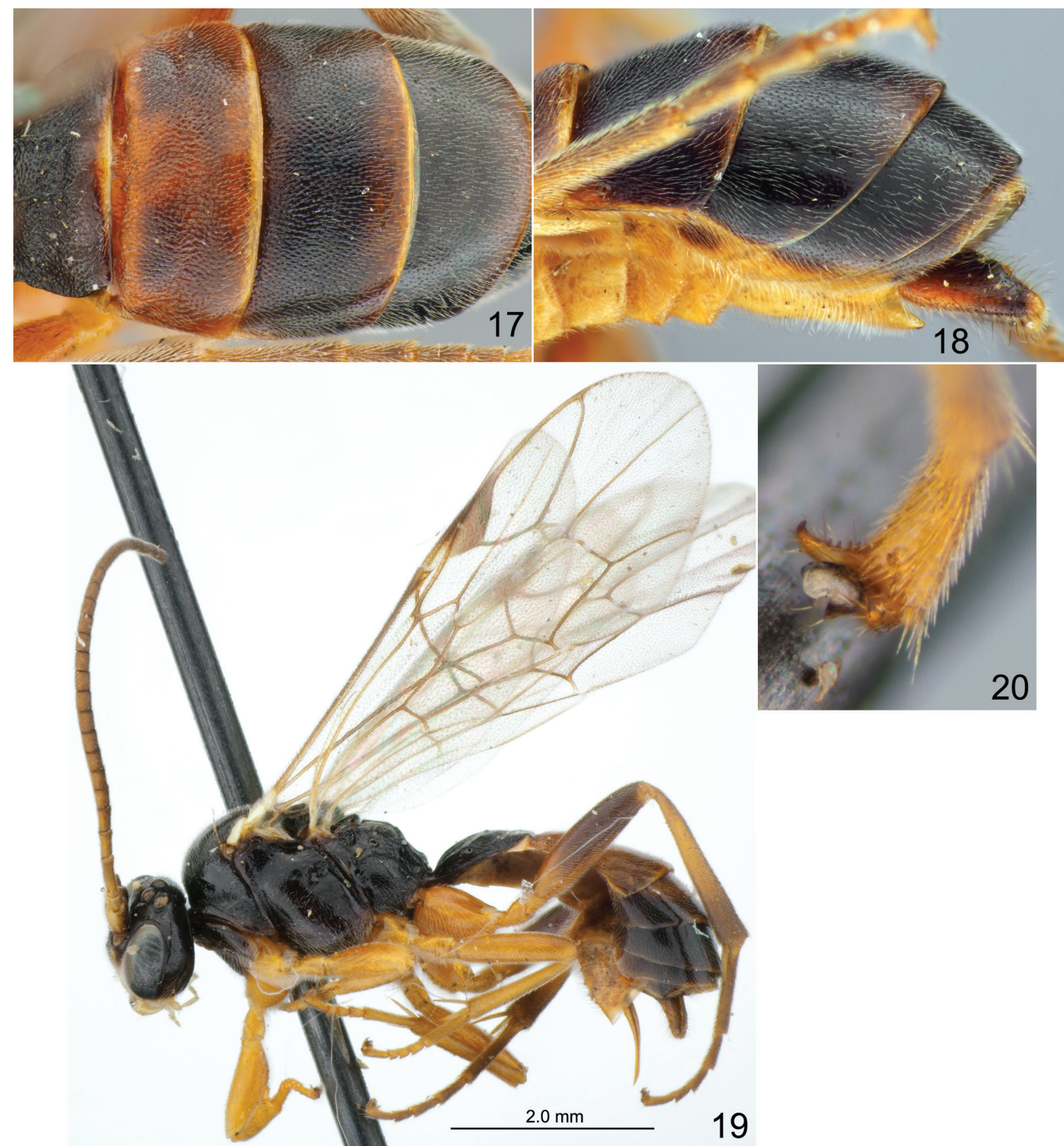

Figures 17-20. Ctenochira arkadyi sp. nov., holotype, female $\mathbf{1 7}$ tergites 2-4, dorsal view $\mathbf{1 8}$ apex of metasoma, lateral view. Ctenochira magnusi, female $\mathbf{1 9}$ habitus, lateral view $\mathbf{2 0}$ apex of hind tarsus.

malar space, palps, mandible (except for teeth) and part of gena from level of lower 0.3 of eye to mandible whitish. Mesosoma black; small spot in hind corner of pronotum whitish, tegula and plates at base of fore wing white. Fore and mid legs and hind coxa light reddish yellow, all trochanters yellow. Hind femur light brown, pale reddish in basal 0.2; hind tibia dull yellowish with apical 0.2 light brown. Metasomal tergites black, tergites 2 and 3 reddish, and tergite 4 in one specimen with small reddish marking at base. Sternites brown with yellow median longitudinal fold on sternites 1-5 (or 6).

Material examined. 1 female, 2 males (ZISP), Russia, $24 \mathrm{~km} \mathrm{~S}$ of Khabarovsk, Khekhzir Ridge, Levaya River, 11.IV.1983, coll. Kasparyan.

Distribution. Norway, Germany, Russia (south of Far East). 


\section{Acknowledgements}

We are thankful to Kazuhiko Konishi (EUM) for loaning specimens, to Gavin R. Broad (London, UK) and Andrei E. Humala (Petrozavodsk, Russia) for reviewing the manuscript, and to Vladimir E. Gokhman (Moscow, Russia) for his valuable comments and corrections. This work was supported by the Russian Foundation for Basic Research (grant no. 19-04-00027) and the State Research Project no. AAAAA19-119020690101-6.

\section{References}

Balueva EN, Khalaim AI, Leei J-W, Kim K-B (2014) A new species of the genus Probles Förster (Hymenoptera: Ichneumonidae: Tersilochinae) from South Korea. Journal of Asia-Pacific Entomology 17(3): 613-616. https://doi.org/10.1016/j.aspen.2014.06.003

Haraldseide H (2018) A new species of Ctenochira Förster, 1855 (Hymenoptera, Ichneumonidae, Tryphoninae). Norwegian Journal of Entomology 65: 26-31.

Horstmann K (1971) Revision der europäischen Tersilochinen I (Hymenoptera, Ichneumonidae). Veröffentlichungen der Zoologischen Staatssammlung (München) 15: 47-138.

Horstmann K (1981) Revision der europäischen Tersilochinen II (Hymenoptera, Ichneumonidae). Spixiana, Suppl. 4(1980): 1-76.

Kasparyan DR (1973) Hymenoptera. Vol. 3. Issue 1. Ichneumon flies (Ichneumonidae). Subfamily Tryphoninae. Tribe Tryphonini. Series "The fauna of the USSR. New Series. No. 106, Hymenoptera”. Nauka, Leningrad, 320 pp. [In Russian] [English translation: Kasparyan DR (1981) Fauna of the USSR, Hymenoptera. Volume III, Number 1. Ichneumonidae (subfamily Tryphoninae). Tribe Tryphonini. New Delhi: Amerind Publishing Co. Pvt. Ltd. (published for the United States Department of Agriculture and National Science Foundation, Washington, D.C.). 414 p.]

Kasparyan DR (2013a) A new Palaearctic species of the genus Ctenochira Förster (Hymenoptera: Ichneumonidae: Tryphoninae), parasitoid of gall-forming sawflies (Hymenoptera: Tenthredinidae: Nematinae) on poplar and willows. Proceedings of the Zoological Institute RAS 317(3): 262-267.

Kasparyan DR (2013b) Description of new species of the genus Ctenochira Förster, 1855 (Hymenoptera, Ichneumonidae: Tryphoninae) from the Eurasian Subarctic Subzone and Siberia, with remarks on the ichneumonid fauna of the Chukchi Peninsula. Entomological Review 93(9): 1155-1178. https://doi.org/10.1134/S0013873813090078

Kasparyan DR (2019) Subfamily Tryphoninae. In: Belokobylskij SA, Samartsev KG, Il'inskaya AS (Eds) Annotated catalogue of the Hymenoptera of Russia. Volume II. Apocrita: Parasitica. Proceedings of the Zoological Institute RAS, Supplement 8: 426-441.

Kasparyan DR, Khalaim AI (2007) 2. Subfamily Tryphoninae. In: Lelej AS (Ed.) Keys to the insects of the Russian Far East, Vol. IV. Neuropteroidea, Mecoptera, Hymenoptera. Part 5. Dalnauka, Vladivostok, 334-404. [In Russian].

Kasparyan DR, Tolkanitz VI (1999) Ichneumonidae. Subfamily Tryphoninae: tribes Sphinctini, Phytodietini, Oedemopsini, Tryphonini (addendum), Idiogrammatini. Subfamilies 
Eucerotinae, Adelognathinae (addendum), Townesioninae. Series "Fauna of Russia and neighbouring countries". New series, no. 143. Insecta Hymenoptera. Volum[e] III, Number 3. Nauka, St. Petersburg 405 pp. [In Russian]

Khalaim AI (2011) Tersilochinae of South, Southeast and East Asia, excluding Mongolia and Japan (Hymenoptera: Ichneumonidae). Zoosystematica Rossica 20(1): 96-148. https:// doi.org/10.31610/zsr/2011.20.1.96

Khalaim AI (2014) Three new species of the genus Probles Förster (Hymenoptera: Ichneumonidae: Tersilochinae) from the Russian Far East. Proceedings of the Russian Entomological Society 85(1): 103-113. https://doi.org/10.47640/1605-7678_2014_85_1_103

Khalaim AI (2018) A new remarkable species of Probles with clavate antennae from Vietnam (Hymenoptera: Ichneumonidae: Tersilochinae). Zoosystematica Rossica 27(2): 234-238. https://doi.org/10.31610/zsr/2018.27.2.234

Khalaim AI (2019) Four new species of the genus Probles Förster (Hymenoptera: Ichneumonidae: Tersilochinae) from Vietnam. Zoosystematica Rossica 28(1): 120-131. https://doi. org/10.31610/zsr/2019.28.1.120

Khalaim AI, Sheng M-L (2009) Review of Tersilochinae (Hymenoptera, Ichneumonidae) of China, with descriptions of four new species. ZooKeys 14: 67-81. https://doi.org/10.3897/ zookeys.14.141

Khalaim AI, Tereshkin AM (2019) Faunistic records and description of two new species of Tersilochinae (Hymenoptera: Ichneumonidae) from Russia and other countries. Zoosystematica Rossica 28(2): 333-355. https://doi.org/10.31610/zsr/2019.28.2.333

Khalaim AI, Balueva EN, Kim K-B, Lee J-W (2013) Three new species of the genus Probles Förster (Hymenoptera, Ichneumonidae, Tersilochinae) from South Korea. ZooKeys 348: 77-88. https://doi.org/10.3897/zookeys.348.6177

Khalaim AI, Balueva EN, Lee J-W (2017) Two new species of the genus Probles Förster (Hymenoptera: Ichneumonidae: Tersilochinae) from South Korea and Russian Far East. Entomological Research 47(1): 48-54. https://doi.org/10.1111/1748-5967.12186

Klopfstein S, Bernardo FS, Shaw MR, Alvarado M, Bennett AMR, Dal Pos D, Giannotta M, Herrera Florez AF, Karlsson D, Khalaim AI, Lima AR, Mikó I, Sääksjärvi IE, Shimizu S, Spasojevic T, van Noort S, Vilhelmsen L, Broad GR (2019) Darwin wasps: a new name heralds renewed efforts to unravel the evolutionary history of Ichneumonidae. Entomological Communications 1: ec01006. https://doi.org/10.37486/2675-1305.ec01006

Townes HK (1969) The genera of Ichneumonidae, Part 1. Memoirs of the American Entomological Institute 11: 1-300. https://doi.org/10.1007/BF02027741

Townes HK, Townes M (1949) A revision of the genera and of the American species of Tryphonini (Hymenoptera: Ichneumonidae). Part I. Annals of the Entomological Society of America 42(3): 321-396. https://doi.org/10.1093/aesa/42.3.321

Yu DSK, van Achterberg C, Horstmann K (2016) Taxapad 2016, Ichneumonoidea 2015. Database on flash-drive. Nepean, Ontario. 